theory seems to me to be natural, and to accord with facts all round, but still it may be wrong. Those, however, who would assign all elevation and subsidence to secular cooling and tangential thrusts through shrinkage are revelling in their own imaginations, for there is no reason why the earth's nucleus should not have cooled as evenly as a cannon ball or piece of pottery, or other homogeneous body; and the records of the Palæozoic rocks, when we may suppose shrinkage would be more active, certainly show that its surface was then relatively level, and without deep seas or great elevations on land.

J. Starkie Gardner

P.S.-A good example of subsidence may be seen in the Tilbury Dock works in progress. So far as I could see, Thames mud is being cut through to a depth of some ninety feet, the upper part at least being filled with debris of reeds interstratified with peaty matter or decayed reeds massed together. The whole must have been deposited at or near high-water level, and so recently that at thirty feet depth the decayed vegetable matter still smells offensive.

\section{The Apparent Disappearance of Jupiter's Satellites on October I4}

RAIN fell without intermission on the afternoon and evening of October I4, but at IIh. it ceased and the clouds broke. Later in the night the sky cleared, but there were showers at short intervals.

At I $5 \mathrm{~h}$. $15 \mathrm{~m}$. I observed Jupiter with a-ro-inch reflector, power about 212 , and saw that the third satellite was the only one visible. It was situated close to the east limb, and its disk appeared somewhat faint, as if much clouded over with spots.

15h. $55 \mathrm{~m}$. - The third satellite is entering upon the planet's disk at a point in the same latitude as the upper side of the great south equatorial belt. The fourth satellite is also seen coming off the west limb. It looks remarkally taint. At this time the configuration of the planet was extremely interesting with the two satellites hanging upon the limbs.

r $6 \mathrm{~h}$. om. - The fourth satellite appears to have completed its egress, and is evidently much in advance of the time given in the Nautical Almanac.

I6h. $15 \mathrm{~m}$. - The first has now reappeared from occultation at a point in the same latitude as the north equatorial belt. This belt is a far more prominent feature than during the last opposition.

I6h. I9m. - A large white patch on the planet's equator is crossing the central meridian. On its north side the equatorial belt is very dark.

16h. 3om. - The third satellite is visible as a very dark spot projected upon the south equatorial belt, which is the darkest belt upon the planet.

I 7 h. om. - The second satellite is seen as a bright spot on the interior margin of the west limb, and will shortly begin its egress. It has crossed Jupiter in a latitude corresponding with the equatorial edge of the great south belt. The third satellite is now perceptible as a black spot pursuing its course along the south belt. The chief condensation of shading apparently lies on the south side of the satellite, but the telescopic image is not satisfactory.

The disappearance of the satellites on this occasion can hardly be said to have been complete, for at no time were they all included within the margin of Jupiter. While the third entered upon the disk the fourth released itself, and the two formed a curious configuration hanging upon the limbs. The third and fourth :atellites were extremely faint when clear of the divk, and their surfaces are evidently very feebly reflective compared with that of their primary. It is significant that the third, though projected upon the darkest belt of Jupiter, was visible as a black spot. The fourth probably crossed the planet as a black spot also, though $\mathrm{I}$ made no attempt to distinguish it under this aspect, owing to frequent interruptions by clouds and rain.

Bristol, October 15

W. F. Denning

\section{Arithmetical Notation of Kinship}

IT serms to me that the elegant arithmetical notation for ancestror: proposed by Mr. Galton in his recent letter to NATURE (September 6, p. 435) may be further simplified. The modification consists in first counting the grades and then counting the species of the grades, as shown in the following diagram :-

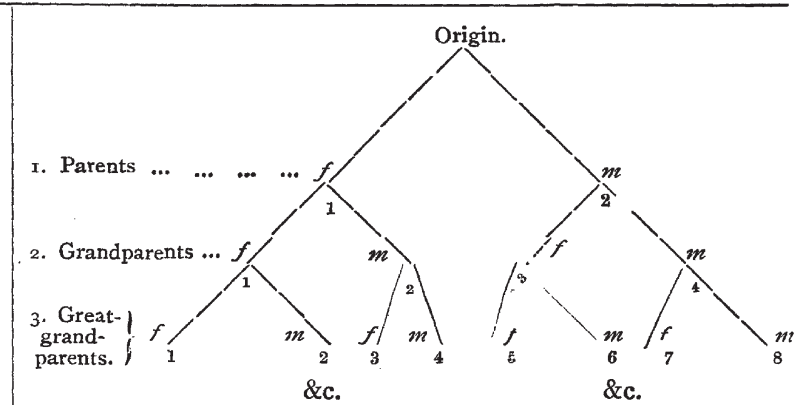

Thus mother of mother of father is of the 3 rd grade and of the $4^{\text {th }}$ species, and may be denoted by 3,4 . Let $q$ denote any grade and $r$ any species, then $q, r$ is a complete specification for an ancestor. The rule for analysing such a specification isDivide $r$ by 2 , adding a unit.when the dividend is odd, and repeat the operation $(q-I)$ times ; then when $r$ or a quotient is odd, substitute father, and when even mother.

Take, for example, 3, 5. We get $5,3,2$, hence father of father of mother. Take 5, 5, we get $5,3,2,1,1$, hence $f f m f f$.

If we compare together the ancestors of the same species number, we shall find that they have all the figures the same until we come to unity, and that the generic difference depends on the number of unities. The truth of this may also be seen by considering the mode of construction of the diagram.

Mr. Galton's 253 is, in this notation, 7, 126. Analysing we get-

$$
\begin{array}{ccccccc}
126 & 63 & 32 & 16 & 8 & 4 & 2 \\
m & f & m & m & m & m & m
\end{array}
$$

The ancestor 7, I of my notation is $\mathrm{I} 28$ in his. The analysis of the latter is-

I $28, \quad 64, \quad 32, \quad 16, \quad 8, \quad 4, \quad 2$, while that of the former is evident by inspection, namelyI, I, I, I, I, I, I.

With the double notation we know that when we come to unity, each of the following. symbols must be $f$; and that when we come to a power of 2 , each of the following symbols must be $m$, followed it may be by some $f$ 's.

4, Gladstone Terrace, Edinburgh

Alexander Macfariane

\section{A Green Sun}

IN connection with the phenomenon recorded in your last number ( $\mathrm{p} .575$ ), the following extract from my journal (Sunday, July 14, 1878), when just north of the Arctic Circle on board the Fonas Lie, may be of some interest:-

"To-night the sun sets in a sky as pure and cloudless as that of yesterday; but the colours are quite different. Now there is no crimson, but in its place orange, yellow, and molten gold. All this exquisite beauty of colour is limited to a particular part of the sky, and that not the west, but the north. Yes, strange as it may seem, the sun sets scarcely a single point from the north, and rises again nearly in the same place, barely two points apart. Some heights are lighted up with the glow, but for most of the time all around, save in the bright, favoured north, is cloudless darkness and gloom; which yet is not the darkness of night, but a grim, stormy, vague gloom in broad daylight. The afterglow that follows sunset dies out, and without any sensible interval of time, revives nearly in the same place; the colour brightens, and some small streaks of clouds grow brighter and brighter, until the sun-the GREEN sun-appears. A distant low range of rocks comes between us and its point of rising, and, as we glide on, an opening between them shows us the sun, abright emerald, as pure and brilliant as ever gem that glistened; again we lose it, and again an opening shows it to us in its own golden light; and then once more it is the bright green : and now it rises higher, clears the ridge, and is once more the golden orb. This is what we saw, but another observer assures us that when first he saw it, the colour was a fiery red, which soon turned to green. Probably an optical effect of what is called polarisation of light, as these complementary colours seem to show." ("A Long Day in Norway," published in The Month in 1878-9.)

All Hallows College, Dublin, October I3 